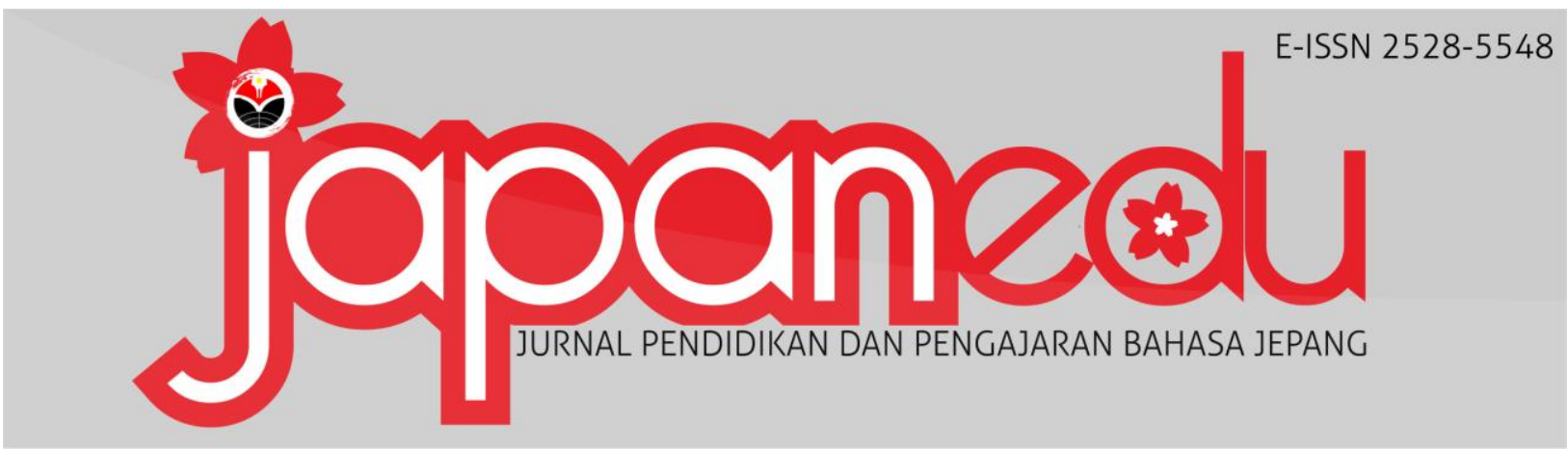

\title{
EFEKTIVITAS MEDIA PERMAINAN SUDOKUDALAM MENGHAFAL HURUF KANA (Menggunakan Metode Eksperimen Quasi Terhadap Siswa Japanese Club SMP Laboratorium Percontohan UPI)
}

\author{
Konstantina Adinda Putrilani ${ }^{1}$, Renariah $^{2}$, Neneng Sutjiati ${ }^{3}$ \\ Departemen Pendidikan Bahasa Jepang, Universitas Pendidikan Indonesia, Jl. Dr. Setiabudhi No. \\ 229, Bandung 40154, Indonesia
}

Email: kadindaputrilani@gmail.com

\begin{abstract}
Abstraksi
Ketika mempelajari bahasa Jepang di sekolah, aspek dasar yang harus dipelajari siswa adalah huruf Jepang. Dalam sistem penulisan, bahasa Jepang memiliki empat huruf, yaitu huruf kanji, hiragana, katakana, dan roomaji. Tetapi sebelum tahap belajar huruf kanji, terlebih dahulu siswa mempelajari huruf hiragana dan katakana yang biasa disebut huruf kana. Huruf kana terdiri atas 96 huruf dimana huruf hiragana dan huruf katakana tersebut bentuknya mirip. Hal ini menyebabkan siswa kesulitan untuk mempelajari huruf kana. Oleh karena itu, diperlukan suatu media untuk mempermudah pembelajar mempelajari huruf kana. Salah satu media yang dapat digunakan adalah media permainan. Dalam penelitian ini, media permainan yang digunakan adalah media permainan sudoku yang sudah di modifikasi. Tujuan dari penelitian ini adalah untuk mengetahui kemampuan siswa dalam pembelajaran huruf kana, sebelum dan sesudah menggunakan media permainan sudoku. Selain itu, penelitian ini bertujuan untuk menganalisis pengaruh penggunaan media permainan sudoku terhadap pembelajaran huruf kana, dan untuk mengetahui respon siswa terhadap penggunaan media permainan sudoku. Penelitian ini menggunakan metode experimen quasi dengan desain eksperimen yaitu one group pre-test post-test. Sampel penelitian adalah anggota Japanese Club sebanyak 20 orang yang diambil dari populasi SMP Laboratorium Percontohan UPI Bandung. Instrumen yang digunakan adalah tes, angket dan obsevasi. Berdasarkan hasil analisis data, nilai thitung sebesar 6.53. Nilai $t$ tabel sebesar 2.09 pada taraf signifikansi 5\% dan 2.86 pada taraf signifikansi 1\%. Dengan demikian, diperoleh hasil $t$ hitung lebih besar dibandingkan nilai $t$ tabel pada taraf signifikansi $5 \%(6.53>2.09)$. Hal ini menunjukkan bahwa pengguanaan media permainan sudoku dalam pembelajaran huruf kana sangat efektif. Selain itu, berdasarkan hasil analisis data angket, responden memberikan tanggapan yang positif terhadap penggunaan media permainan sudoku yaitu menarik, dan mudah diikuti.
\end{abstract}

Kata kunci: Efektivitas, Media Permainan Sudoku, Huruf Kana 


\begin{abstract}
When studying Japanese at school, basic aspects must study is the Japanese letter. In its writing system, Japanese has four letters, namely kanji, hiragana, katakana, and roomaji. Before the stage of kanji learning, firstly, students have to learn hiragana and katakana which are commonly called kana. Kana, composed of 96 letters where the letter of the hiragana and katakana are barely different. This causes difficulties for students to learn kana. Therefore, we need a media to facilitate learners to learn kana. One medium that can be used are game as the learning media. This study, the media used is a sudoku game that has been modified. The purpose of this study is to acknowledge students' ability in learning kana, before and after using the sudoku game as a media. In addition, this study also aims to analyze the influence of sudoku game usage as the media in learning kana Letters, and to find out the students' response to the use of sudoku game as a media. This study uses a quasi experiment method with the one group pre-test - post-test as experiment design. Samples were 20 students from Japanese Club members who were taken from a population of SMP Laboratorum Percontohan UPI Bandung. The instrument used was test, questionnaire and observation. Based on the data analysis, the t value at 6.53 . T table at 2.09 on a significance level of $5 \%$ and 2.86 at $1 \%$ significance level. Thus, the results obtained that $t$ value is greater than $t$ table at a significance level of $5 \%(6.53>2.09)$. This shows that the usage of sudoku game as media is a very effective in learning kana. In addition, based on data analysis of the questionnaire, the respondents gave a positive response to the use of media sudoku game that are attractive, and easy to follow
\end{abstract}

Keywords : Effectivity, Sudoku Game Media, Kana Letters

\title{
PENDAHULUAN
}

Huruf dalam bahasa Jepang disebut moji, monji, ataupun ji (Sudjianto, 2004: 55). Termasuk didalamnya terdapat huruf-huruf Kanji, Hiragana, Katakana, dan roomaji. Orang Jepang bisa menulis setelah mengenal aksara Tionghoa yang disebut biasa disebut Kanji. Kanji jaman dahulu dipakai untuk menulis sastra klasik, namun karena Kanji dinilai susah dengan kerumitan bentuknya, maka peneliti sastra tersebut yang saat itu adalah seorang wanita membuat huruf Hiragana. Hiragana digunakan untuk menulis kata-kata Jepang asli atau menulis partikel dan kata bantu. Berbeda halnya dengan Katakana, dikatakan bahwa Katakana adalah huruf yang dibuat oleh lakilaki dilihat dari coretannya yang tegas.
Katakana biasanya dipakai untuk istilah istilah asing yang masuk ke Jepang. Katakana biasa digunakan untuk menulis bahasa sandi rahasia, surat-surat penting perusahaan, atau buku-buku yang berhubungan dengan perkantoran.

(http://bacaterus.com/tulisan-dan-hurufjepang/, diakses 13 Maret 2016)

Hal pertama yang harus dipelajari siswa dalam mempelajari bahasa Jepang adalah mempelajari huruf Hiragana dan Katakana yang biasa disebut huruf Kana. Huruf Kana sangatlah penting untuk dipelajari agar nantinya siswa lebih mudah untuk mempelajari bahasa Jepang lebih dalam lagi. Tetapi, untuk mempelajari huruf Kana dimana masing-masing berjumlah 46 huruf, 
selain itu, cara penulisan huruf Hiragana dan Katakana haruslah sesuai dengan aturan, belum lagi bentuk huruf Hiragana dan Katakana yang terlihat mirip.

Hal ini membuat siswa kesulitan untuk mempelajari bahasa Jepang lebih dalam, karena siswa harus menghafal banyak huruf baru. Oleh sebab itu, tugas sebagai pengajar adalah mencari cara supaya pembelajaran dapat menjadi lebih mudah dan menyenangkan. Salah satu upaya agar belajar menjadi lebih menyenangkan adalah dengan bermain. Mahendra (dalam Sopianti, 2014: 3) menjelaskan bahwa "bermain dapat menimbulkan keriangan, kelincahan, relaksasi dan harmonisasi sehingga seseorang cenderung bergairah. Kegairahan dapat memudahkan timbulnya inspirasi sehingga anak-anak dapat dengan mudah melakukannya tanpa harus ada paksaan atau hambatan".

Oleh sebab itu, penulis ingin mengujicobakan sebuah permainan yaitu permainan Sudoku. Sudoku juga dikenal sebagai Number Place atau nanpure, adalah sejenis tekateki logika. Tujuannya adalah untuk mengisikan angka-angka dari 1 sampai 9 ke dalam jaring-jaring 9x9 yang terdiri dari 9 kotak $3 \times 3$ tanpa ada angka yang berulang di satu baris, kolom, atau kotak. Sudoku (数 独 ) adalah singkatan bahasa Jepang dari “Suuji wa dokushin ni kagiru” (数字は独身
に限る), artinya “angka-angkanya harus tetap tunggal".

Permainan Sudoku merupakan permainan yang membutuhkan konsentrasi yang tinggi karena pemain harus berpikir dengan cepat. Dalam penelitian ini, penulis mengubah angka-angka yang harus diisi dalam Sudoku menjadi huruf Kana, dan juga kotak 9x9 yang biasa dipakai Sudoku, penulis ubah menjadi $6 \times 6$ yang terdiri dari 6 kotak $3 \times 2$. Menurut penulis permainan ini bisa menjadi alternatif untuk mempelajari huruf Kana, karena siswa harus menghafal bentuk huruf Kana. Jadi permainan Sudoku ini secara tidak langsung memaksa siswa untuk memperhatikan materi yang diajarkan dan mengingatnya, khususnya pada materi pembelajaran huruf Kana.

Berdasarkan penjabaran diatas, peneliti mencoba mengubah permainan suudoku yang harusnya berisi angka, menjadi huruf Hiragana dan Katakana. Oleh karena itu peneliti mengambil judul penelitian "Efektivitas Media Permainan Sudoku Dalam Menghafal Huruf Kana" untuk dijadikan sebuah skripsi.

Berdasarkan latar belakang masalah yang telah diuraikan di atas, maka peneliti merumuskan masalah sebagai berikut:

1. Bagaimana hasil belajar siswa sebelum dan sesudah melaksanakan permainan Sudoku?

2. Bagaimana efektivitas permainan Sudoku dalam menghafal huruf 
Kana di SMP Laboratorium

Percontohan UPI?

3. Bagaimana respon siswa terhadap permainan Sudoku dalam menghafal huruf Kana?

Sesuai dengan rumusan masalah yang telah disebutkan, tujuan umum dari penelitian ini adalah sebagai berikut:

1. Untuk mengetahui penguasaan huruf sebelum dan sesudah siswa menggunakan media permainan Sudoku.

2. Untuk mengetahui efektivitas penggunaan media permainan Sudoku dalam menghafal huruf kana.

3. Untuk mengetahui bagaimana respon siswa terhadap permainan Sudoku.

Di sini akan dipaparkan beberapa pengertian belajaran menurut para ahli.

Adapun menurut Komalasari (2011: 1-2) bahwa "Hakikat belajar adalah perubahan seseorang yang asalnya tidak tahu menjadi tahu merupakan hasil dari proses belajar". Misalnya Ghifari yang tadinya tidak dapat berbahasa Inggris sekarang mahir berbahasa Inggris. Akan tetapi, tidak semua perubahan yang terjadi dalam diri seseorang merupakan hasil proses belajar. Ciri-ciri kegiatan belajar yaitu :

1) Belajar adalah aktivitas yang dapat menghasilkan perubahan dalam diri seseorang, baik secara aktual maupun potensial.

2) Perubahan yang didapat sesungguhnya adalah kemampuan yang baru ditempuh dalam jangka waktu yang lama.

3) Perubahan terjadi karena ada usaha dari dalam setiap diri individu.

Menurut Gagne (dalam buku Komalasari, 2011: 2) mendefinisikan "Belajar sebagai suatu proses perubahan tingkah laku yang meliputi perubahan kecenderungan manusia seperti sikap, minat, atau nilai dan perubahan kemampuannya yakni peningkatan kemampuan untuk melakukan berbagai jenis Performance (kinerja)". Sedangkan menurut Sunaryo (1989: 1) "Belajar merupakan suatu kegiatan dimana seseorang membuat atau menghasilkan suatu perubahan tingkah laku yang ada pada dirinya dalam pengetahuan, sikap dan keterampilan. Sudah barang tentu tingkah laku tersebut adalah tingkah laku yang positif, artinya untuk mencari kesempurnaan hidup".

Berdasarkan pendapat beberapa ahli tersebut penulis memiliki pandangan yang sama dengan Komalasari dikarenakan adanya ciri-ciri kegiatan belajar yang dapat dirasakan oleh setiap individu. Sedangkan pendapat dari Gagne dan Sunaryo, menyatakan bahwa belajar adalah perubahan tingkah laku dan peningkatan kinerja seseorang dalam melakukan kegiatan yang mengarah kepada kegiatan positif. 
Menurut Sumiati (2009: 160) media pembelajaran diartikan sebagai segala sesuatu yang dapat digunakan untuk menyalurkan pesan (message), merangsang pikiran, perasaan, perhatian dan kemauan siswa sehingga dapat mendorong proses belajar. Bentuk-bentuk media pembelajaran digunakan untuk meningkatkan pengalaman belajar agar menjadi lebih konkrit. Pembelajaran dengan menggunakan media pembelajaran tidak hanya sekedar menggunakan kata-kata (symbol verbal). Dengan demikian, dapat kita harapkan hasil pengalaman belajar lebih berarti bagi siswa. Dalam hal ini Gagne dan Briggs (1979) menekankan pentingnya media pembelajaran sebagai alat untuk merangsang proses belajar.

Berikut akan dijelaskan manfaat media permainan dalam pembelajaran.

Permainan merupakan salah satu cara terbaik untuk mengumpulkan fokus siswa untuk belajar, terutama untuk pembelajaran huruf Kana. Berikut ini manfaat permainan dalam pembelajaran menurut Kemp dan Dayton, yaitu:

1) Proses pembelajaran lebih menarik

2) Proses belajar siswa menjadi lebih interaktif

3) Jumlah waktu belajar mengajar dapat dikurangi

4) Kualitas belajar siswa dapat ditingkatkan

5) Proses belajar dapat dimana saja dan kapan saja
6) Sikap positif terhadap bahan pelajaran maupun terhadap proses belajar itu sendiri dapat ditingkatkan

7) Peran guru dapat berubah kearah yang lebih positif dan produktif

Sebagai media pendidikan menurut Pertiwi (2009: 19) permainan mempunyai beberapa kelebihan, yaitu:

1) Permainan adalah sesuatu yang menyenangkan untuk dilakukan, menghibur dan menarik.

2) Permainan memungkinkan adanya partisipasi aktif dari siswa untuk belajar.

3) Permainan dapat memberikan umpan balik langsung.

4) Permainan memungkinkan siswa untuk memecahkan masalahmasalah nyata.

5) Permainan memberikan pengalamanpengalaman nyata dan dapat diulangi sebanyak yang dikehendaki, kesalahan-kesalahan operasional dapat diperbaiki.

6) Membantu siswa meningkatkan kemampuan komunikatifnya.

7) Membantu siswa yang sulit belajar dengan metode tradisional.

8) Permainan bersifat luwes, dapat dipakai untuk berbagai tujuan pendidikan. Permainan dapat dengan mudah dibuat dan diperbanyak. 


\section{METODE PENELITIAN}

Dalam penelitian ini, metode yang digunakan adalah penelitian eksperimen. Penelitian eksperimen atau penelitian uji coba merupakan salah satu metode yang sering digunakan dalam bidang pengajaran. Tujuan metode ini yaitu untuk menguji efektivitas dan efesiensi dari suatu pendekatan, metode, teknik atau media pengajaran dan pembelajaran, sehingga hasilnya dapat diterapkan jika memang baik, atau tidak digunakan jika memang tidak baik, dalam pengajaran yang sebenarnya (Sutedi, 2011: 64). Desain eksperimen yang digunakan dalam penelitian ini adalah preexperimental yaitu penelitian yang hanya terdapat satu kelas tanpa adanya kelas kontrol/kelas pembanding. Jenis penelitian yang digunakan adalah one group pretestposttest.

Sampel dalam penelitian ini adalah 20 orang anggota Japanese Club SMP Laboratorium Percontohan UPI Bandung. Alasan dilihnya siswa Japanese Club sebagai sampel adalah karena hanya siswa yang menjadi anggota japanese club yang bisa menulis huru kana.

Desain penelitian yang diterapkan dalam penelitian ini adalah pretest and posttest design. Adapun alur desain penelitian ini sebagai berikut:

\section{$\begin{array}{lll}\mathbf{O}_{1} & \mathbf{X} & \mathbf{O}_{2}\end{array}$}

Keterangan:

$\mathrm{O}_{1}$ : pretest

$\mathrm{X}$ : treatment

$\mathrm{O}_{2}$ : posttest

Penelitian ini dilakukan enam kali pertemuan. Pertemuan pertama dilakukan pretest dan menjelaskan tujuan penelitian. Kemudian melakukan treatment pertama pada pertemuan kedua, treatment kedua pada peremuan ketiga, treatment ketiga pada pertemuan keempat, treatment keempat pada pertemuan kelima. Petemuan keenam diisi dengan kegiatan posttest dan pengisian angket yang berisi tentang pendapat responden mengenai penggunaan media permainan sudoku dalam menghafal hururf kana.

Huruf kana yang digunakan dalam treatment ini hanyalah 92 huruf kana dasar, yaitu：あ、い、う、え、お、か、き、く 、け、こ、さ、し、す、せ、そ、た、ち 、つ、て、と、な、い、ぬ、ね、の、は 、ひ、ふ、へ、ほ、ま、み、む、め、も 、や、ゆ、よ、ら、り、る、れ、ろ、お 、を、ん untuk huruf hiragana dan ア、イ 、ウ、エ、オ、カ、キ、ク、ケ、コ、サ 、シ、ス、セ、ソ、タ、チ、ツ、テ、ト 、ナ、ニ、ヌ、ネ、ノ、ハ、ヒ、フ、へ ホ、マ、ミ、ム、メ、モ、ヤ、ユ、ヨ 
、ラ、リ、ル、レ、ロ、ワ、タ、ン

untuk huruf katakana.

Pada setiap treatment, siswa diajarkan perbedaan huruf hiragana dan katakana terlebih dahulu, kemudian siswa dibagi perkelompok dan mengerjakan papan permainan sudoku. Setelah itu bersama-sama dengan siswa mengerjakan sudoku yang digambar dipapantulis.

\section{HASIL DAN PEMBAHASAN}

Berdasarkan hasil yang diperoleh bahwa nilai rata - rata siswa pada pre-test adalah 65.5. Angka tersebut menunjukan bahwa kemampuan siswa dalam pembelajaran huruf Kana dinyatakan cukup. Sedangkan nilai rata - rata pada saat post-test adalah 91.25. Angka tersebut menunjukan bahwa kemampuan siswa dalam mempelajari huruf Kana dinyatakan sudah sangat baik.

Dengan demikian dapat disimpulkan bahwa hasil pre-test dan hasil post-test pada umumnya mengalami peningkatan. Kemudian dengan menggunakan media permainan Sudoku dapat membantu pembelajaran huruf Kana. Selain dari hasil pretest dan posttest, berdasarkan hasil perhitungan statistik, diperoleh $t$ hitung sebesar 6.53 dan t tabel untuk db 19 sebesar 2.09 pada taraf signifikansi $5 \%$ dan 2.86 pada taraf signifikansi 1\%. Maka dari itu, diperoleh hasil bahwa $t$ hitung lebih besar dibandingkan nilai $t$ tabel pada taraf signifikansi $5 \%(6.53>2.09)$. Hasil tersebut membuktikan bahwa setelah diberikannya treatment dengan menggunakan media permainan Sudoku sebanyak empat kali pertemuan, Hk diterima karena ada pengaruh yang signifikan dari penggunaan media permainan Sudoku terhadap pembelajaran huruf Kana.

Berdasarkan analisis data angket, diketahui bahwa penggunaan media permainan Sudoku terhadap pembelajaran huruf Kana mendapat respon positif. Hal ini dilihat dari jawaban angket yang menyatakan hampir seluruh sampel menjawab bahwa belajar huruf Kana menggunakan media permainan Sudoku itu menyenangkan, menarik dan mudah diikuti.

Dalam pembelajaran huruf Kana menggunakan media permainan Sudoku menjadi suatu inovasi baru yang dapat memacu siswa untuk belajar lebih semangat dan mengembangkan kreativitas juga konsentrasi sehingga menjadi lebih aktif di kelas. Selama proses pembelajaran dengan menggunakan media permainan Sudoku ini, suasana di kelas Japanese Club menjadi sangat menyenangkan dan mengakrabkan sesama anggota $c l u b$.

\section{KESIMPULAN}

1) Hasil data penelitian menunjukkan hasil bahwa sebelum diberikan treatment, nilai rata-rata pre-test 
menunjukkan angka 65.5. Setelah diberikan treatment menggunakan media permainan sudoku dalam pembelajaran huruf kana, nilai posttest memperoleh peningkatan dengan nilai rata-rata 91.25. Kemudian berdasarkan hasil analisis perhitungan statistik, diperoleh nilai thitung sebesar 6.53.

2) Berdasarkan hasil analisis perhitungan statistik, diperoleh nilai t hitung sebesar 6.53 yang kemudian dibandingkan dengan $t$ tabel untuk db 19 sebesar 2.09 pada taraf signifikansi $5 \%$ dan 2.86 pada taraf signifikansi 1\%, maka diperoleh hasil $t$ hitung lebih besar dibandingkan nilai $t$ tabel pada taraf signifikansi $5 \%(6.53>2.09)$. Hasil ini menunjukkan bahwa $\mathrm{Hk}$ (hipotesis kerja) diterima karena terdapat perubahan yang signifikan dari penggunaan media permainan sudoku dalam pembelajaran huruf kana. Dengan demikian media permainan sudoku efektif dalam menghafal huruf kana.

3) Berdasarkan hasil data angket yang telah diisi oleh 20 orang sampel, dapat diambil kesimpulan bahwa pembelajaran huruf kana dengan menggunakan media permainan sudoku $100 \%$ menarik, 95\% memudahkan pembelajaran huruf kana, $80 \%$ mudah mengikuti alur permainan sudoku, dan $85 \%$ memotivasi siswa untuk belajar huruf kana. Selain itu, sebagian besar responden merasa bahwa penggunaan media permainan sudoku menyenangkan dan dapat meningkatkan kemampuan responden dalam mengahafal huruf kana sehingga pengunaan media permainan sudoku dapat dijadikan alternatif untuk mempelajari huruf kana.

4) Berdasarkan hasil data angket yang telah diisi oleh 20 orang sampel, dapat diambil kesimpulan bahwa penggunaan media permainan sudoku dalam pembelajaran huruf kana mendapat respon yang sangat baik dan positif. Hal ini karena penggunaan media permainan sudoku membuat responden lebih rileks dalam mempelajari huruf kana, dan lebih mudah untuk mengingat dan membedakan huruf hiragana dan huruf katakana. 


\section{PUSTAKA RUJUKAN}

[1] Arikunto, Suharsimi. (2010). Prosedur Penelitian Suatu Pendekatan Praktek. Jakarta : Rineka Cipta.

[2] Komalasari, K. (2011). Pembelajaran Kontekstual Konsep Dan Aplikasi. Bandung : PT Refika Aditama.

[3] Sopianti, Novia. (2014). Efektivitas Permainan Ketok Palu Untuk Memotivasi Siswa Dalam Menguasai Huruf Hiragana dan Katakana (Penelitian Ekspreimen Terhadap Siswa SMA Pasundan 8 Bandung Kelas XI Tahun Ajaran 2012/2013). Skripsi pada FPBS UPI: tidak diterbitkan.

[4] Pertiwi, Devi. (2009). Efektivitas Teknik Permainan Acak Huruf Hiragana Dalam Meningkatkan Penguasaan Kosakata I-Keyoushi Bahasa Jepang.
Skripsi pada FPBS UPI: tidak diterbitkan.

[5] Sumiati dan Asra. (2009). Metode Pembelajaran. Bndung : CV Wacana Prima.

[6] Sunaryo. (1989). Strategi Belajar Mengajar Ilmu Pengetahuan Sosial. Malang : Penerbit IKIP Malang.

[7] Sutedi, Dedi. (2011). Penelitian Pendidikan Bahasa Jepang. Bandung : Humaniora.

[8] http://bacaterus.com/tulisan-dan-hurufjepang/ (Diakses 13 Maret 2016) 